\title{
DIAGNOSA KEPERAWATAN PADA ASUHAN KEPERAWATAN DI RUMAH SAKIT
}

\author{
Wanda Miftah Fatihah \\ Email : wandamiftah22@gmail.com
}

\begin{abstract}
Abstrak
Diagnosis keperawatan adalah suatu kegiatan penilaian yang dilakukan oleh perawat berdasarkan respon yang diberikan pasien secara holistik terhadap penyakit atau gangguan kesehatan yang sedang dialaminya. Diagnosis keperawatan sama pentingnya serta memiliki muatan etis dan aspek legal yang sesuai dengan diagnosis medis. Maka diagnosis keperawatan merupakan suatu kunci perawat dalam membuat rencana asuhan yang diberikan pada pasien yang sedang dirawat.
\end{abstract}

Kata kunci : Diagnosis keperawatan, Rencana asuhan keperawatan.

\begin{abstract}
A nursing diagnosis is an assessment activity conducted by a nurse based on the patient's holistic response to the illness or health disorder he or she is experiencing. Nursing diagnosis is equally important and has an ethical charge and legal aspects that correspond to medical diagnosis. Therefore, nursing diagnosis is a key part of making care plans given to patients who are being treated.
\end{abstract}

Keywords : Nursing diagnosis, Nursing care plan. 


\section{Latar Belakang}

Dalam melaksanakan asuhan keperawatan, perawat akan melalui tahapan dalam proses keperawatan. Proses keperawatan ini terdiri dari pengkajian, diagnosis, perencanaan intervensi, perencanaan hasil, implementasi, dan evaluasi.

Salah satu yang penting dalam proses keperawatan adalah pengkajian keperawatan. Pengkajian keperawatan sangat penting agar perawat mampu menentukan masalahkeperawatan/diagnosa yang dialami oleh pasien yang sedang di rawat.

Diagnosa keperawatan merupakan suatu penilaian mengenai respon pasien, komunitas, dan keluarga mengenai masalah kesehatan yang aktual yang diperoleh melalui pengkajian perawatan klien dan perawat akan menyuimpulkan atau memecahkan masalah yang di alami lasien.

Perawat melakukan diagnosis keperawatan jika mampu berkerja sama seperti melakukan validasi data, dan revisi diagnosis mengenai status kesehatan pasien.

Namun $\quad$ perawat belum
menerapkan standar asuhan yang
terdokumentasi

sebagai aspek legal dalam pelayanan keperawatan. Namun, dari penelitian sebelumnya belum memaparkan aspek kualitas dokumentasi asuhan keperawatan secara deskriptif untuk memberikan gambaran jelas aspek mana dari proses keperawatan yang sering kali penerapannya tidak sesuai dengan standar yang ada.

Selain itu, dirasa perlu mengukur gambaran aplikasi standar berdasarkan standar yang dikeluarkan oleh organisasi profesi sebagai acuan dalam penetapan standar asuhan keperawatan di Indonesia.

\section{Metode}

Metode yang dilakukan dalam penulisan kajian ini yaitu dengan cara menganalisis mengeksplorasi membaca dari referensi yang berkaitan dengan diagnosa keperawatan melalui referensi yang berbeda seperti jurnal, tesis, text book yang didapatkan dengan memuat Google Scholar dengan memasukkan kata kunci sesuai dengan judul kajian dengan memasukkan kata kunci "diagnosis keperawatan"

\section{Hasil}

Berdasarkan hasil referensi literature yang dilakukan pada kajian ini, didapatkan mengenai " diagnosa keperawatan pada asuhan keperawatan di 
rumah sakit" dalam literatur ini yang telah dilakukan dari beberapa sumber kajian atau penulisan mendapatkan hasil yaitu diagnosa keperawatan sangat penting dilakukan pada proses asuhan keperawatan karena memungkinkan perawat untuk menganalisis apa yang terjadi dengan pasien diagnosa keperawatan dapat diarahkan kepada sasaran individu atau keluarga

\section{Pembahasan}

Menurut NANDA pada tahun 1994 didefinisikan diagnosa keperawatan yaitu diagnosa yang menjelaskan Respon yang dialami oleh manusia terhadap tingkat kesejahteraan keluarga komunitas serta individu itu sendiri yang memiliki potensi untuk menuju kondisi yang lebih tinggi dan lebih baik lagi.

Langkah-langkah yang dilakukan tenaga kerja keperawatan di rumah sakit dalam melakukan diagnosa keperawatan pada asuhan keperawatan dapat dilakukan dengan cara mengumpulkann data pasien yang akurat, analisis data serta pengelompokan data prosedur.

Pada pengumpulan data atau melakukan pengkajian ini didukung dengan penegakan diagnosa keperawatan seperti prosedur untuk mendukung diagnosa resiko dan aktual.
Pada saat pengkajian, perawat juga perlu mempertimbangkan dan memperhatikan pelaksanaan proses kesehatan sedang berlangsung pada diri pasien.

Suatu proses akan mempermudah perumusan diagnosa keperawatan jika perawat memperhatikan perilaku klien.

Saat dilakukannya suatu proses, klien harus dapat menyelesaikan beberapa langkah atau tahapan sebelum mencapai sasaran.

Dengan mengidentifikasi perilaku dan langkah yang dilakukan oleh klien, perawat dapat menilai kemajuan dalam menyelesaikan proses dan menggunakan informasi tersebut untuk merumuskan diagnosa keperawatan.

Menurut Stolte pada tahun 2004, telah merumuskan sejumlah proses yang dapat digunakan dalam diagnosa keperawatan. Proses tersebut meliputi perolehan informasi baru, dapay penyembuhan luka, menjadikan suatu pembelajaran keterampilan baru, serta peningkatan status fungsional fisik.

Menurut PPNI tahun 2009, mengatakan bahwa diagnosis keperawatan dapat divalidasi oleh klien atau pasien. 
Pada diagnosa yang dibuat diterima oleh sesama keperawatan sebagai diagnosa yang benar, signifikan atau relevan Hal ini dapat memudahkan perawat untuk merencanakan mengevaluasi meneliti suatu keadaan pasien untuk menentukan asuhan keperawatan yang selanjutnya.

Hasil pengkajian yang dilakukan oleh perawat di Rumah Sakit mengenai diagnosa akan dinilai secara langsung yaitu dengan cara memberikan Asuhan Keperawatan yang berkualitas dan dilakukannya dokumentasi asuhan keperawatan.pelayanan.

Menurut Nursalam (2009), Penulisan dan pendokumentasian diagnosa keperawatan memiliki kriteria yang harus diketahui, yaitu:

1. Menulis bagaimana perkembangan kondisi kesehatan pasien.

2. Memastikan masalah kesehatan pasien didahului penyebab dan dihubungkan dengan

kata "berhubungan dengan”.

3.. Menulis istilah yang diketahui semua orang (Umum) dan mudah dipahami

5. Menggunakan bahasa yang memvonis.

6. Memastikan pernyataan masalah mencantumkan keadaan yang tidak sehat atau keadaan pasien yang dapat berubah.
7. Menghindari penggunaan definisi karakteristik, diagnosis, atau sesuatu yang tidak bisa diubah dalam pernyataan masalah.

8. Membaca ulang diagnosa keperawatan untuk memastikan pernyataan yang benar. alitas yang ada pada keperawatan.

\section{Penutup}

\section{Kesimpulan}

Dari hasil kajian yang saya lakukan mengenai diagnosa keperawatan dalam asuhan keperawatan mendapatkan kesimpulan yaitu saat melakukan asuhan keperawatan diperlukan untuk melakukan diagnosa keperawatan. perlunya diagnosa keperawatan ini untuk mengevaluasi, dan merevisi format catatan keperawatan yang telah dilakukan sesuai dengan kebutuhan pasien.

\section{Daftar Pustaka}

Efendy, M. (2012). Perbedaan Tingkat Kualitas Dokumentasi Proses Keperawatan Sebelum Dan Sesudah Penerapan NANDA-I, NIC, Dan NOC. Jurnal Keperawatan Soedirman, 7(2), 67-77

Eriyani. (2020). Dokumentasi Keperawatan. Medan: Sekolah Tinggi Ilmu Kesehatan Binalita Sudama Medan. 
Hidayat, A. (2015). Model Documentation

Of Assessment And Nursing Diagnosis In The Practice Of Nursing Care Management For Nursing Students. Journal Of Advanced Nursing Studies, $4(2), 158-163$.

Koerniawan, D., Daeli, N. E., \& Srimiyati. (2020). Aplikasi Standar Proses Keperawatan: Diagnosis, Outcome,Dan Intervensi Pada Asuhan Keperawatan. Jurnal Keperawatan Silampari , 3 (2) . 739-751.

Mailani, F., \& Ramadini, I. (2020). Pedampingan Dan Pelatihan Pendokumentasian Keperawatan Di Puskesmas Lubuk Buaya Padang. Jurnal Abdimas Saintika ,2 (2). 5-13.

Mugianti, S. (2016 ). Manajemen dan Kpemimpinan dalam Praktik Keperawatan. Jakarta Selatan: Pusdik SDM Kesehatan.

Novieastari, E. (2003). Diagnosa Keperawatan Sejahtera. Jurnal Keperawatan Indonesia, 7(2). 77-80.

Rinawati, P. (2018). Kompetensi Perawat Dalam Merumuskan Diagnosa Keperawatan Pada Pasien Di Ruang Rawat Inap Rsud Tugurejo Semarang. 19.

Simamora, R. H., Bukit, E., Purba, J. M., \& Siahaan, J. (2017). Penguatan kinerja perawat dalam pemberian asuhan keperawatan melalui pelatihan ronde keperawatan di rumah sakit royal prima medan. Jurnal pengabdian kepada masyarakat, 23(2), 300-304.

Simamora, R. H. (2019). Socialization of Information Technology Utilization and Knowledge of Information System Effectiveness at Hospital Nurses in Medan, North Sumatra. Editorial Preface From the Desk of Managing Editor. International Journal of Advanced Computer Science and Applications(IJACSA). 10(9). 177-121

Suarni, L. (2017). Efektifitas The 6 Steps Reasoning Diagnosis Method dan Intan,s Clinical Reasoning Model (ICRM) dalam Penentuan Standar Asuhan Keperawatan (SAK) pada Setting Keperawatan Maternitas. Jurnal Kesehatan , 8 (3). 337-344.

Winarsih, B. D., \& Widiyaningsih, H. (2013). Panduan Praktik Klinik Keperawatan Komprehensif 2. Kudus: Penerbit Media 